BAPL, 36. 2002 (191-199)

\title{
PALABRAS CHINAS EN EL DICCIONARIO DE LA ACADEMIA DE LA LENGUA ${ }^{1}$
}

\author{
Joseph Cruz Soriano \\ Traductor e intérprete de la Sociedad Central de \\ Beneficencia China del Perú
}

Como toda lengua sujeta al intercambio y tráfico de la cultura, el comercio, la ciencia y la política, el español ha incrementado su vocabulario mediante el aporte de otras lenguas. Así, en diferentes épocas y por diferentes motivaciones, en particulares coyunturas históricas, el español ha tomado y toma palabras del latín y del griego (que tienen por decírlo así, el carácter de formadoras), del árabe, del inglés, del francés, del italiano, del alemán y de lenguas amerindias. También, en menor proporción, han entrado palabras del sánscrito, el persa, el japonés y el chino.

\section{INTRODUCCIÓN}

En el caso del chino, en la vigésima primera edición del Diccionario de la Real Academia Española (DRAE) contamos sólo ocho palabras, de las cuales dos son de uso muy común: charol y té; mientras que en el lenguaje técnico tiene cierto uso caolin, que designa cierto tipo de arcilla. El tratamiento etimológico de las voces de esta procedencia ha enfrentado 
largo tiempo un problema derivado de la escritura china: la transliteración al español, esto es, la representación de los sonidos chinos mediante letras del alfabeto latino que se usa en Occidente, siempre ha sido difícil. Sólo en décadas recientes se ha superado esta dificultad debido a que los mismos chinos recién han tomado interés en la romanización de su escritura.

Habiendo examinado las palabras de origen chino que aparecen en el DRAE, podemos formular dos observaciones generales:

1) En la parte etimológica —que aparece entre paréntesis al lado de la palabra, en negritas, que se va a definirno son exactas las designaciones "Del chino" (por ser muy genérica), "chino mandarín" o "chino pequinés".

2) La transliteración es completamente deficiente, pues no representa adecuadamente las consonantes ni da indicación alguna del tono de cada palabra. Como sabemos, en chino el tono determina el significado de la palabra de modo semejante a como en español se diferencian miro y miró, publico y publicó. En chino tenemos, por ejemplo, en cantonés los pares $\mathrm{mai}_{5}$ ('comprar'), $\mathrm{mai}_{6}$ ('vender'), y en mandarín $s \check{I}$ ('muerte') sì ('cuatro'), que aunque tienen las mismas vocales y consonantes portan significaciones diferentes únicamente en virtud del tono con que se pronuncia cada una, representado mediante un número en subíndice en el caso del cantonés y con un acento diacrítico especial para el mandarín.

\section{LAS PALABRAS Y COMENTARIO}

En seguida transcribimos las palabras de etimología china tal como las presenta el DRAE.

caolín. (Del chino kaoling, alta colina, nombre del lugar donde se encontró, a través del fr. Kaolin.) m. Arcilla blanca muy pura que se emplea en la fabricación de porcelanas, aprestos y medicamentos. 
Observaciones.1) Es muy genérico decir "chino"; debe ser "chino mandarín"; 2) la transliteración debe ser gāo ling; 3) además, debemos aclarar que la expresión completa es gão líng tŭ, literalmente tierra [de] Kao Ling', nombre que en chino se da a la arcilla en mención.

champán'. (Del chino san pan, tres tablas, a través del malayo.) m. Embarcación grande, de fondo plano, que se emplea en China, Japón y algunas partes de América del Sur para navegar por los ríos.

Observaciones. 1) No es "chino" sino "chino mandarín"; 2) el nombre original es shān băn, expresión oral y escrita que designa específicamente a este tipo de embarcación. Sin embargo, por lo complicado del primer carácter, al momento de tomar notas a mano se escribe sān băn ('tres tablas'), ya que en algunas provincias del sur de China no se diferencia bien la sh de la s. Obsérvese que shãn băn y sān băn tienen el mismo tono en ambas sílabas.

charol. "Del chino chat liao, a través del port. charão.) m. Barniz muy lustroso y permanente, que conserva su brillo sin agrietarse y se adhiere perfectamente a la superficie del cuerpo a que se aplica. | [...]

Observaciones. 1) No es "chino" sino "chino cantonés"; 2) la transliteración correcta es $t s e t_{7} y e u_{4}$; 3) En mandarín 'charol' es qi liàu, cuya / inicial ayudaría a explicar la $r$ del portugués, puesto que esta lengua muchas veces convierte en $r$ la $l$ de otros idiomas, como branco por 'blanco' y emprego por 'empleo'.

cha. (Del chino mandarín, a través del port. cha, té.) m. p. us. En Filipinas y algunos países hispanoamericanos, té.

Observaciones. El carácter chino que representa la palabra "té" se pronuncia en diferentes formas según los diversos dialectos regionales del idioma chino. Por ejemplo, en mandarín chá, en catonés $t s a_{4}$, en shanghainés $z \breve{u}$, en dialecto Lung Tu (Zhong Shan, Guangdong) se pronuncia ta $\mathrm{t}_{4}$, etc. De lo que 
vemos, las formas que más se prestan para explicar el cha portugués son el mandarín chá o el cantonés $t s a_{4}$.

chinchín ${ }^{3}$. (Del chino pequinés ching-ching a través del inglés chinchin.) Expresión que acompaña el choque de copas o vasos en un brindis.

Observaciones. En las diversas variedades del chino no existe una palabra semejante a "chinchín" que se emplee en brindis. Por ello es posible que esta entrada del DRAE sea derivación del pequinés $q$ ing (la $q$ representa una consonante africada palatal) 'por favor', que se utiliza como exortación cuando una persona no hace lo que se le pide, que en este caso sería un llamado a servirse el licor.

jangua. (Del chino chun, barco.) m. Embarcación pequeña armada en guerra, muy usada en los mares de Oriente.

Observaciones. Para empezar, notamos que la palabra del DRAE es de dos sílabas mientras que su presunto étimo chino tiene solamente una. En chino mandarín existe la idea de barco de guerra, que se expresa con zhàn chuán, literalmente 'guerra barco', lo que nos permite notar que al segundo elemento de la transliteración del diccionario falta la letra $a$. Es muy necesario mencionar que en la parte español-chino del diccionario bilingüe que consultamos (véase la Bibliografía) figura la palabra jangua, pero al definir no ponen -como sucede, por ejemplo, en el caso de caolín-los caracteres que debieran corresponderle sino que la describen indicando que es un tipo de nave del Oriente, lo cual indicaría o bien que el étimo de jangua está constituido por palabras muy antiguas o desusadas, cuyos caracteres no se conocen ahora, o bien no que es una palabra de origen chino.

sangley. (Del chino šang-lúi, a través del tagalo sanglay.) adj. Decíase del chino que pasaba a comerciar a Filipinas. Ú. t. c. s. $\| 2$. Por ext., chino residente en Filipinas. Ú. t. c. s. 
Observaciones. 1) Es chino cantonés; 2) La transliteración es $\mathrm{San}_{1} \mathrm{lai}_{4}$, cuyo significado es, literalmente, 'recién llegado'.

té. (Del chino tscha, pronunciado en ciertas provincias te.) $\mathrm{m}$. Arbusto del Extremo Oriente, de la familia de las teáceas, que crece hasta cuatro metros de altura, con las hojas perennes, alternas, elípticas, puntiagudas, dentadas y coriáceas, de seis a ocho centímetros de largo y tres de ancho; flores blancas, pedunculadas y axiladas, y fruto capsular, globoso, con tres semillas negruzcas.[...]

Observaciones. 1) Es chino cantonés; 2) la transliteración "tscha" es incorrecta, ya que las consonantes africadas chinas se representan con dos letras o con una (por ej., $t s, c h, q$, etc.), no con tres; debe ser tè (pronunciación del dialecto de Chao Zhou, Guandong). Véase la explicación de cha.

\section{INCLUSIÓN DE NUEVAS VOCES}

En esta sección proporcionamos información linguística sobre raíces chinas que explican algunos peruanismos. He aquí las palabras:

arroz. [...] $\|$ chaufa. (Del chino cantonés $t s e u_{2} f a n_{6}$, cocinar arroz cocido.) Perú. Plato que se prepara salteando en sartén cebolla china, carne picada, huevo frito picado, jengibre y salsa de soya, que se combina con arroz cocido.

chifa. Posiblemente del chino contonés $\operatorname{sik}_{9} \mathrm{fan}_{6} l a_{3}$, a comer arroz cocido.) m. Perú. Restaurante de comida china. \|2. Perú. Comida que se prepara en un chifa, o que se prepara al modo de los chinos.

chinchin $^{2}$. (Del chino cantonés $t \sin _{4}$, dinero.) fr. Perú, al chinchín. En efectivo, contante y sonante.

kung fu. (Del chino cantonés gung, $f u_{l}$, artes de lucha a mano libre.) m. Perú. Artes marciales chinas. 
quion o kion (Del chino cantonés gœク , jengibre.) m. Perú jengibre.

sillao o siyao. (Del chino catonés $s i_{6} \quad y e u_{4}$.) m. Perú. Salsa de soya.

sopa. [...] || wantán. (Del chino cantonés $w_{e n}$ tan $_{1}$.) Perú. La que se hace con fideos rellenos de carne, col china y otros ingredientes.

Observaciones. Es una expresión cantonesa cuya traducción literal sería 'tragar nubes'.

taipá. (Del chino cantonés $d a i_{6} b a_{2}$, abundante.) adj. Perú. Colmado, lleno, abundante.

tusán. (Del chino cantonés $t o u_{2} s e \eta_{1}$, nacido en el lugar.) com. Perú. Descendiente de padres chinos nacido en el extranjero.

Observaciones. El significado original en chino permite aplicar esta expresión no sólo a chinos, de manera que en chino se dice "tusán chino", "tusán japonés" y "tusán inglés", etc. Según esto, "tusán japonés" y "tusán inglés" son los hijos nacidos en el extranjero de padres japoneses o de padres ingleses.

wantan. (Del chino cantonés wen $_{4} \tan _{1}$.) m. Perú. Pasta de harina con relleno de carne sazonada, a modo de ravioles. $\|$ frito. Perú. El que se fríe y se come con salsa de tamarindo.

\subsection{ANOTACIONES}

Sobre estas palabras tendríamos que precisar algunos puntos.

Respecto de chifa debemos mencionar que hay otra explicación etimológica que aparentemente cuadra mejor: se 
trata de postular $d z y_{2} \mathrm{fan}_{6} l a_{3}$ ('vamos a cocinar arroz cocido'). La objeción que tenemos es desde el punto de vista práctico o pragmático, puesto que lo de cocinar es válido o significativo mucho más para los que están en la cocina (cocineros, dueño, etc.) que para los que fuera, los que vienen de la calle (los comensales), para quienes la noción de comer es pertinente. Por otra parte, se podría objetar cómo de una palabra con s inicial (como $s^{2} k_{9}$ en $s_{i} k_{9} f o n_{6} l a_{3}$ ) surge chifa, con $c h$ inicial; frente a esto, hay que observar en el DRAE cómo una palabra con ch inicial como champán" ("Embarcación grande, de fondo plano, que se emplea en China, Japón...") procede de $\operatorname{san}_{4}$ pan $_{2}$ que presenta $s$ inicial.

2) En cuanto a quion o kion, hay que señalar que en el Perú es la única palabra que designa al jengibre, nombre desconocido el uso normal de los peruanos. Escribimos su transliteración mediante gœ $\eta_{1}$, cuya "g" inicial podría dar la impresión de que la pronunciación es con "g"”, como en gato, góndola, etc. No es así: en la transliteración del chino se tiene en cuenta si las consonantes son aspiradas o no aspiradas; en consecuencia, los chinos han optado por usar $p, t, k$ para las consonantes oclusivas aspiradas sordas, y $b, d, g$ para las consonantes oclusivas no aspiradas sordas. Según esto, por ejemplo, la $p$ vale por la pe aspirada / $\mathrm{p}^{\mathrm{h}} /$, y la $b$ por la $p e$ no aspirada $/ \mathrm{p} /$; mientras que la $k$ representa la $k a$ aspirada $/ \mathrm{k}^{\mathrm{h}} /$, y la $g$ va por la $k a$ no aspirada $/ \mathrm{k} /$.

4 CONCLUSIONES

La revisión de las palabras de origen chino que están registradas en el DRAE y la propuesta de inclusión de nuevas voces (peruanismos) de esa procedencia nos permiten plantear las siguientes conclusiones:

1) Considerando que en el Perú casi el $100 \%$ de emigrantes chinos proceden de la sureña provincia de Cantón (Guandong), de los que en un inicio más del 60\% fueron 
hablantes nativos del dialecto hakká (etnia han proveniente de la cuenca del río Amarillo que migró al sur en cinco grandes oleadas, desde el s. IX d. C. hasta el siglo XIX), y tanto en Norteamérica como en el resto del mundo la mayoría de los emigrantes ha sido de origen cantonés, la mayoría de palabras chinas que han entrado al léxico de otros idiomas proviene o bien del habla cantonesa o bien del hakká. Muy poco, casi nada, ha venido del chino mandarín. En consecuencia, en la etimología de estas voces se debe especificar "(Del chino cantonés..., Del chino mandarín..., etc.)"

2) En la transliteración, considerando que el origen de las palabras es cantonés, es necesario marcar los tonos con números en subíndice. El cantonés posee 9 tonos, lo que hace necesario - para establecer las diferencias de significadorecurrir a números en la transliteración. Veamos: fán ('molestar', 'molesto' (adj.)') fàn ('infringir'), făn ('revés') y fān ('traducir').

\section{BIBLIOGRAFÍA}

Academia Española

1973

Esbozo de una nueva gramática de la lengua española, Madrid, Espasa Calpe S. A.

1992 Diccionario de la lengua española, 2 t., Madrid, Espasa Calpe S. A., 21. ${ }^{\circledR}$ edición.

Derpich, Wilma E.

1999

El otro lado azul / 150 años de inmigración china al Perú, Lima, Fondo Editorial del Congreso del Perú.

Facultad de Lengua Española del Instituto Superior de Lenguas Extranjeras de Beijing

1981

Nuevo Diccionario Español-Chino / Xin xihán cídiăn, Beijing, Facultad de Lengua Española 
del Instituto Superior de Lenguas Extranjeras de Beijing.

Instituto Superior Sociológico de China

1980

Xiàndài hànyŭ cídiăn, Beijing, Instituto Superior Sociológico de China.

Laussnt-Herrera, Isabelle

2000

Sociedades y templos chinos en el Perú, Lima, Fondo Editorial del Congreso del Perú.

Seco, Manuel

1998

Diccionario de dudas y dificultades de la lengua española, Madrid, Espasa Calpe S. A., 10. edición.

Shang Wu, Yin Shu Guan

1991

Shäng wù xìn zidiăn, Hong Kong, Shan Wu Yin Shu Guan. 